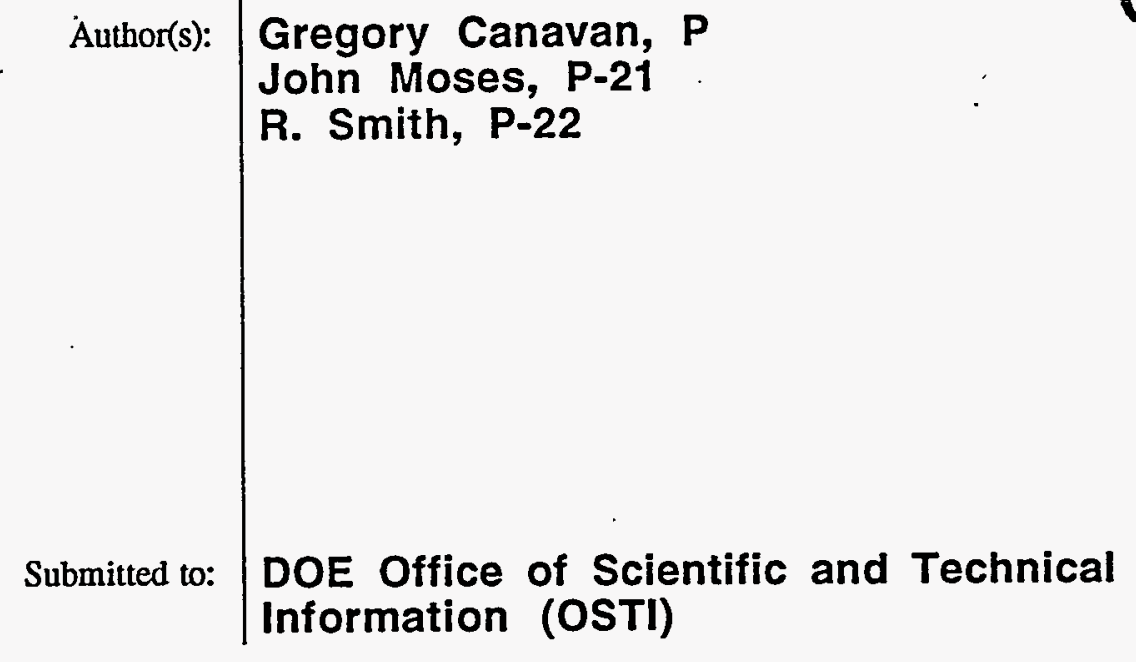

DISCLAIMER

This report was prepared as an account of work sponsored by an agency of the United States Government. Neither the United States Government nor any agency thereof, nor any of their employees, makes any warranty, express or implied, or assumes any legal liability or responsibility for the accuracy, completeness, or usefulness of any information, apparatus, product, or process disclosed, or represents that its use would not infringe privately owned rights. Reference herein to any specific commercial product, process, or service by trade name, trademark, manufacturer, or otherwise does not necessarily constitute or imply its endorsement, recommendation, or favoring by the United States Government or any agency thereof. The views and opinions of authors expressed herein do not necessarily state or reflect those of the United States Government or any agency thereof.
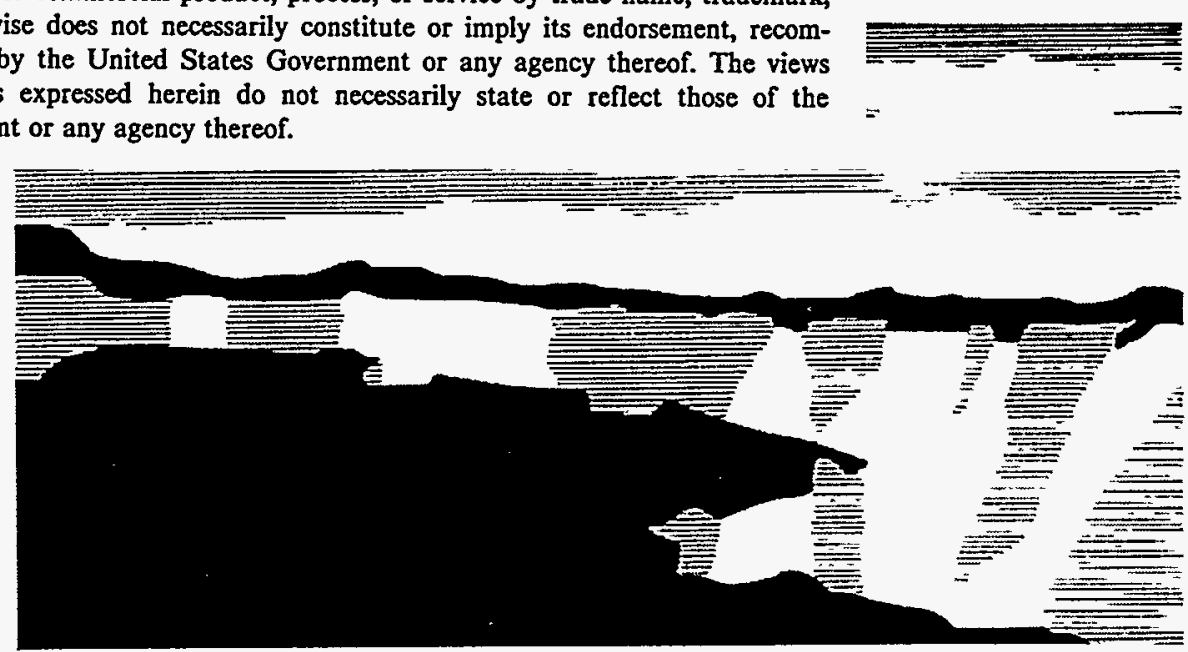

Los Alamos Nallonal Laboratory, an aftirmative action/equal opportunity employer, is operated by the University of California for the U.S. Department of Energy under contract W-7405-ENG-36. By acceptance of this article, the publisher recognizes that the U.S. Government relains a nonexclusive, royaltyfree license to publish or reproduce the published form of this contribution, or to allow others to do so, for U.S. Government purposes. The Los Alamos Nalional Laboratory requests that the publisher identify this article as work periormed under the auspices of the U.S. Department of Energy. 


\title{
Hyper-Spectral Scanner Design and Analysis
}

\author{
Gregory Canavan*, John Moses, and R. Smith
}

\begin{abstract}
This is the final report of a two-year, Laboratory Directed Research and Develpoment (LDRD) project at the Los Alamos National Laboratory (LANL). An earlier project produced rough designs for key components of a compact hyper-spectral sensor for environmental and ecological measurements. Such sensors could be deployed on unmanned vehicles, aircraft, or satellites for measurements important to agriculture, the environment, and ecologies. This represents an important advance in remote sensing. Motorola invited us to propose an add-on, proof-of-principle sensor for their Comet satellite, whose primary mission is to demonstrate a channel of the IRIDIUM satellite communications system. Our project converted the preliminary designs from the previous effort into final designs for the telescope, camera, computer and interfaces that constitute the hyper-spectral scanning sensor. The work concentrated on design, fabrication, preliminary integration, and testing of the electronic circuit boards for the computer, data compression board, and interface board for the camera-computer and computer-modulator (transmitter) interfaces.
\end{abstract}

\section{Background and Research Objectives}

Earlier projects produced rough designs for key components of a compact hyperspectral sensor for environmental and ecological measurements (Barrett, et. al. 1991, Canavan and Barrett 1991, Borel and Canavan 1994). Such sensors could be deployed on drones, aircraft, or satellites for measurements important to agriculture, the environment, and ecology (Canavan and Teller 1991a \& b). Such sensors would represent an important advance in the measurement of key parameters whose global distributions are not known accurately (Canavan and Wood 1991). Motorola recognized that fact and invited us to propose a proof-of-principle, add-on sensor to their "Comet" satellite (Canavan 1995a). Comet's primary mission is to demonstrate a channel of the IRIDIUM satellite communications system, which is to begin deployment in 1996. Comet is a very fast paced program. Motorola's communication link had

* Principal investigator, e-mail: gcanavan@lanl.gov 
already been fabricated and tested, and the satellite was to fly in May 1995. Thus, the experiments had to be ready for delivery for integration with Motorola's payload in February. To meet that schedule, it was necessary to complete the design of our instrument in December, fabricate it in January, and test it in February (Canavan 1994). Los Alamos could meet that schedule through steps discussed below; thus, it was selected to field the experiment. The sensor is a combination of an existing charge-coupled device (CCD) camera, a wedge filter for hyper-spectral resolution, and an existing R3000 flight computer, which were built, integrated, and tested on schedule and have performed satisfactorily on the satellite. The flight portion of the experiment will take images, compress and store them, and transmit them to ground stations as a demonstration of the value of space remote sensing with hyper spectral resolution as a means of assessing the status of vegetation around the globe.

\section{Importance to LANL's Science and Technology Base and National R\&D Needs}

This project supports Los Alamos core competencies in complex experimentation and measurement as well as theory, modeling, and high-performance computing. The technologies - small satellites and compact, well calibrated sensors-are essential to laboratory support of environmental monitoring and global climate change. This approach to remotely screening and cataloging thermal emitters could also be applied to monitoring traffic or land use (Barrett, et. al., 1991). There are also non-proliferation and counter-proliferation applications (Canavan and Worden 1994). Potential DoD customers are the Air Force space and tactical components, other services, and intelligence agencies. These sensors would complement highresolution reconnaissance from complex sensors. It has recently been demonstrated that they can discriminate man-made objects in thick foliage even with modest spatial resolution.

\section{Scientific Approach and Results to Date}

Normally, such a fast-paced schedule would not be possible for the development of space hardware; however, in this case extensive prior work built a base of technology that could be integrated rapidly into the required sensor. The key was the selection of a sensor that was so simple it could be built in the two months allowed, which is about an order of magnitude shorter time than usually needed for an instrument this ambitious. We selected a wedge filter aligned over a CCD array. The wedge filter is aligned so that the frequency of light passed increases in the direction along the satellite's flight (in-track). Thus, at any time, the wedge passes red light from regions behind the satellite, green light from below it, and blue 
light from ahead. As the satellite moves, the wedge passes-and the array measures-light from all frequencies from each point below. The wedge does not differentiate frequencies in the transverse direction; thus, at any time the array images in space in the cross-track direction and in frequency in the in-track direction. As time passes, the satellite's motion causes the sensor to image in the track-wise direction as well. This simple configuration, with no moving parts, images in- and cross-track directions and frequency. Only recently have wedge filters of the uniformity and arrays of the size needed to make the concept practical become available.

The main components of the selected sensor are a $10-\mathrm{cm}$ telescope, a visible CCD camera, and a commercial wedge filter, which produce the required hyper-spectral resolution. The R3000 flight computer processes the data and compresses it into the memory available for storage and bandwidth available for transmission to the ground. For the telescope, camera, and filter, Los Alamos teamed with the Optical Corporation of America (OCA), which has built and flown similar instruments on Brilliant Pebbles and Clementine. Although the schedule was tight for an instrument of this optical quality, OCA's prior experience made it possible for them to meet our fabrication and delivery schedule. The OCA instrument was built to our specifications and acceptance. The OCA delivered their instrument on a schedule consistent with the needs for our functional and environmental test, which it passed without incident. We mated it with the wedge filter and calibrated the combination, which was close enough in uniformity and flatness to require little correction.

The schedule for the flight computer was also very tight. What made it feasible was Los Alamos' extensive experience with the R3000 computer and the availability of the backup R3000 computer for the SAWAFE experiment. Its processor, memory, and power boards could be used directly. Only the data compression and camera and modulator interface board needed to be built. Through related programs, we had identified appropriate compression chips and produced preliminary designs for the interface circuits. Thus, the computer could also meet schedule for completion of the design, fabrication, and testing of the circuit board in the flight computer. It was used for the design and test of generic compression circuitry and was not integrated with funding from Motorola for component and system fabrication and integration.

Executing these preliminary designs and tests over the following few weeks enabled us to maintain the schedule required to meet Motorola's integration and launch deadlines. The full sensor was completed, tested, and integrated into Motorola's satellite, where it remains, awaiting launch for reasons that have to do with the booster, not the satellite. It has been in a state of readiness and checking for a period of several months. 


\section{References}

C. Barrett, G. Canavan, D. Cooper, R. Joseph, A. Saxman, A. Ledebuhr, I. Lewis, L.

Pleasance, W. Scott, and L. Wood, "Applications of Distributed Remote Sensing to Landsat-

Like Sensors," Los Alamos National Laboratory document LA-UR-91-3090, December 1991.

C. Borel and G. Canavan, "Compact Sensors for Small Satellites," LDRD proposal, 1994.

G. Canavan and C. Barrett, "Coverage and Computation from Distributed Surveillance," Los Alamos National Laboratory report LA-12113-MS, 1991.

G. Canavan and E. Teller, "Low-Level Satellites Expand Distributed Remote Sensing," Signal, August 1991, pp. 99-103; "Distributed Remote Sensing for Defense and the Environment," Los Alamos National Laboratory document LA-UR-91-1169, May 1991a.

G. Canavan and E. Teller, "Distributed Remote Sensing for Defense and the Environment," Los Alamos National Laboratory document LA-UR-91-1169, May 1991 b.

G. Canavan and L. Wood, "Distributed Remote Sensing from Constellations of Small Satellites," A. Zichichi, ed., Proceedings of the Annual World Laboratory Meeting: International Seminar on Nuclear War and Planetary Emergencies (World Scientific, Singapore, 1991); Los Alamos National Laboratory document LA-UR-91-2780, September 1991.

G. Canavan and S. Worden, "Military Space in the Next Century," Los Alamos National Laboratory report LA-UR-93-4178, February 1994; presented to the Air Force "Spacecast 2020," Air University, Maxwell Air Force Base, February 1994.

G. Canavan, "Secondary Payloads for Communication Satellites," LA-UR 94-3004, 1994.

G. Canavan, "Value of Remote Sensing Imagery," Los Alamos P/AC-95:851, 1995a.

G. Canavan, "Alternative Architectures," New World Vistas (Montgomery, Al., Air University, in press); Los Alamos LA-UR-95:2191, June 1995b.

G. Canavan, "Should We Engineer the Global Climate?" invited address to the American Association for the Advancement of Science, AAAS National Meeting, San Francisco, 18-23 February 1994; invited review paper, Climate Change (in press), $1995 \mathrm{c}$.

G. Canavan, chairman, "Review of the Mission to Planet Earth Remote Sensors and Satellites," (National Research Council of the National Academy of Sciences, in press), $1995 \mathrm{~d}$.

P. Weber, "LDRD/CD science ideas," 1 September 1995. 